\title{
DISCURSO E METODOLOGIA: tensão na análise ${ }^{1}$
}

No funcionamento da linguagem, como veremos, o seu sujeito é constituído por gestos de interpretação que concernem sua posição. O sujeito é a interpretação. Fazendo significar, ele significa. (ORLANDI, 2001, p. 22).

\section{Marlon Leal Rodrigues ${ }^{2}$ UEMS/NEAD/UNICAMP ${ }^{3}$}

\section{Resumo}

O artigo visa abordar sobre alguns aspectos metodológicos da Análise do Discurso de linha francesa, e principalmente no que se refere à ocupação do MST. Averiguou-se assim o corpus dos editoriais do Jornal do MST que compreendeu o período de 1981 (no. 01, 15/05/1981) até 2004, (no. 240, 05/2004), optou-se pelo editorial por revelar-se ser um espaço que expressa as orientações ideológicas dos enunciados. Logo constatou-se nas análises um equilíbrio importante diante da observância da materialidade discursiva e da abordagem histórica. Desse modo, a análise mostrou-se um enfoque reflexivo dentro da proposta metodológica, delineado dentro de uma diversidade de questões sem esquemas e modelos estruturados.

Palavras-chave: Análise do discurso. MST. Abordagem histórica. Materialidade discursiva.

\section{Introdução}

A Análise do Discurso de linha francesa (AD), ao reivindicar um campo específico para si no domínio da Linguística, ela o faz, mas não da forma que se entende por disciplina da Linguística, ou seja, não da forma tradicional: circunscrever um objeto sem romper com o paradigma no nível da definição de língua e da própria questão metodológica inscrita no estruturalismo. A AD não apenas desestabiliza o "sentido" (PÊCHEUX, 1997) de língua como também rompe a proposta metodológica de Saussure, proposta que deu o status de ciência à Linguística: a definição do objeto e a metodologia de análise. Não bastasse esta intervenção desestabilizadora, a AD ainda vai articular com a Linguística para compor o seu domínio, duas outras áreas do conhecimento, a Psicanálise, relida por Lacan e o Marxismo, na leitura de Althusser.

Esta articulação, de acordo com Pêcheux (1997) e Orlandi (1999), é uma “disciplina de entremeio", não se deixa absorver nem pelo marxismo e nem pela psicanálise, abre o seu próprio espaço de trabalho no limite do linguístico com o social.

\footnotetext{
${ }^{1}$ Este texto faz parte ampliada de minha tese de doutoramento na UNICAMP, orientada pelo Prof. Dr. Sírio Possenti. Agradeço ao CNPq pela bolsa de doutorado (2002-2006).

${ }^{2}$ Professor Adjunto da UEMS - Universidade Estadual de Mato Grosso do Sul, Unidade Universitária de Nova Andradina. NEAD - Núcleo de Estudos em Análise do Discurso.

${ }^{3}$ Pós-Doutoramento supervisionado pela Profa. Dra. Eni P. Orlandi (UNICAMP), 2008.
}

Paranaíba

v. 1

n. 1 p. $66-82$ 2010 
Nesse sentido, entre as diversas rupturas causadas pela AD no domínio da Linguística, Possenti (2005, p. 358-388) enumera: “[...] do campo da interpretação, da língua, da pragmática, do texto, das condições de produção, do sentido, da enunciação, do acontecimento, do interdiscurso e do sujeito". Essas rupturas, em seu conjunto, promovem uma tensão na metodologia (questão "cara" para a AD tanto internamente aos analistas dos discursos quanto aos adversários) e na forma de "observar e analisar" a língua. Pode-se considerar que a metodologia está posta ou na forma de pressupostos ou na forma de implícitos. Trata-se agora de não mais enquadrar os dados nos esquemas prontos a-históricos, mas de colocar questões, de problematizar os dados principalmente naquilo que a Linguística deixou de fora de suas reflexões, o sujeito e a história.

Pode-se, assim, considerar que a proposta metodológica é uma construção do analista que possui como princípio norteador colocar questões e a problematização no confronto com os dados, o que leva a considerar a possibilidade de abstração metodológica como resultado analítico. Em face dessa problematização surge a "entrada" do analista na "descoberta" e na "construção" da metodologia. Nesse sentido, a AD rompe com análises estruturais e deixa ao analista a sua capacidade de lidar com os dados e a habilidade teórica.

A partir destas considerações, a proposta neste texto é abordar uma descrição mais do que discussão sobre alguns aspectos metodológicos em Análise do Discurso de linha francesa desenvolvidas em minha dissertação de mestrado e, posteriormente, tese de doutoramento. Notas de caminhos e descaminhos.

\section{Questões Metodológicas: dissertação}

Segue de forma elementar o objetivo geral da dissertação e a sua problemática que de alguma forma já pressupõe um tipo de entrada na análise:

Este trabalho se inscreve nesse quadro de interdições: a exclusão social que impõe outras formas de interdições, como a da palavra, a do direito à terra, entre outras. Inscreve-se, também, como não poderia deixar de ser, pela natureza dos agentes sociais, em um quadro de luta, de poder e de desejo de transformação social ou de imposição de uma Nova Ordem.

A pesquisa tem como objeto o discurso do Movimento dos Trabalhadores Rurais Sem Terra, o MST. Restringe-se à análise dos editoriais do MST, em sua trajetória histórica (Boletins no. 1 de 15/5/81 ao JST no. 189 de 5/99 - esta data foi contingência do trabalho, início do levantamento), e tem por finalidade levantar o suporte ideológico que dá sustentação às atividades práticas e discursivas do Movimento.

A escolha dos editoriais como objeto de análise justifica-se por serem eles que exprimem, de forma sintética e concisa, as orientações, propostas e bandeiras marcadamente ideológicas daquilo que está no corpo dos boletins e jornais. 
A compreensão dos acontecimentos sociais, de uma perspectiva ideológicodiscursiva, tem dois pressupostos: a presença do sujeito - no caso, agente do MST - e a materialidade do discurso. O processamento da análise do discurso pode possibilitar a verificação da constituição do suporte ideológico sobre o qual o Movimento se sustenta, as ideologias que 'pulsam' em cada enunciado, em cada texto, em cada palavra de ordem. De acordo com Rodrigues (1999: 1), considerando o comentário a respeito da palavra de ordem:

É de praxe nos movimentos sociais a elaboração de palavras de ordem como forma de expressar e dialogar com os demais segmentos sociais, marcando posição ideológica concisão das propostas, reivindicações, origem do movimento [...] A estrutura lingüística da PO pode ser um sintagma nominal, sintagma verbal, uma proposição. (RODRIGUES, 2001, p. 21-22).

Assim, a partir destas considerações iniciais, a metodologia se apresentou como uma questão desde o mestrado ${ }^{4}$ : como analisar? O que analisar? Enfim, como iniciar a análise? Um dos caminhos, além da orientação recebida, foi ler e estudar as análises de outros autores/pesquisadores e procurar entender como eles procediam em suas análises. Disso, extraí algumas lições: o analista precisa conhecer historicamente o seu objeto de pesquisa, porque esse conhecimento vai proporcionar em alguma medida o tipo de análise e sua especificidade, ou seja, o "discurso" (PÊCHEUX, 2002) a ser analisado: elaborar questões pertinentes ao objeto, estabelecer um objetivo geral do qual demanda objetivos específicos, determinar qual o tipo de corpus: oral, escrito, o suporte, o "gênero" (MAINGUENEUAU, 1993, p. 2001) etc. Ao pensar no corpus é importante procurar "visualizar" como consegui-lo, ter acesso a ele e o que ele pode oferecer de recorte que atenda às primeiras elaborações/perguntas sobre o objeto.

De forma muito empírica, ainda no início do mestrado, pesquisei em jornais e em revistas, tudo sobre o MST dos últimos anos. Consegui de doação uma caixa cheia de revistas e jornais do Sindicato dos Profissionais da Educação de Três Lagoas e região (SINTED), que fazia assinaturas. Foi uma caixa (cheia) grande do tipo máquina de lavar roupa; demorei três meses para recortar, colar e organizar em um arquivo. Além de pedir um catálogo de matérias e reportagens de televisão sobre o MST (TV Cultura de São Paulo); as fitas gravadas eram caras demais para serem adquiridas. Tive que desistir logo, pois havia outro problema, teria que transcrever horas e horas de programa de televisão.

Sobre o jornal e a revista, fui conversar com a minha orientadora e ela com poucas perguntas me fez perceber que tudo o que tinha feito era em vão. Perguntou: que tipo de corpus? Que tipo de suporte? Se for o jornal ou revista, o que eles oferecem? Entrevistas do

\footnotetext{
${ }^{4}$ Dissertação de Mestrado em Letras, "Introdução ao Estudo da Ideologia que Sustenta o MST", UFMS Campus de Três Lagoas (2001), orientada pela Profa. Dra. Sílvia Helena Barbi Cardoso.
} 
MST (o movimento falando dele mesmo de forma direcionada) e/ou entrevistas sobre o MST (alguém falando do movimento). Que tipo de jornal/revista: do movimento ou dos meios de comunicação de massa? Depois colocou outra questão: qual vai ser o gênero do discurso?

Não perdi todo o trabalho porque li o material como forma de conhecimento sobre o Movimento: o que os outros "falavam do movimento", o que o movimento "falava" de si e a forma como se "falava" do movimento. Mas, tive que pensar em outro corpus.

Comentando sobre a pesquisa com amigos sobre as "angústias" de pesquisador iniciante, uma amiga disse que tinha a assinatura do Jornal do MST, o que me "animou" de forma considerável, além de resolver muitos dos meus problemas. Consegui o Jornal do MST (defini o corpus), faltava a sua abrangência. Faltava definir o gênero: seriam entrevistas, depoimentos, narrativas, cartas, mensagens, editorial etc.?

A primeira etapa foi conseguir o material da Associação Nacional de Cooperativas Agrárias - SP (ANCA) (do boletim nº 01 de 1981 até a última edição do jornal, pois o boletim se converteu em jornal), ter contato com ele e estabelecer um recorte e abrangência histórica (datas). Já estava definido: escolhi o jornal enquanto suporte, o editorial enquanto gênero, pois nele continha as metas, os objetivos, as questões, as discussões do movimento, o contexto histórico, os conflitos, entre outras informações, orientações. Enfim, era o "discurso" (PÊCHEUX, 2002) do próprio Movimento.

Em relação ao período, resolvi que seria a partir do número um para se ter uma visão do desenvolvimento histórico do Movimento, desde o nascedouro (1981) até o momento da pesquisa (1999).

Umas das maiores dificuldades foi o recorte dos "enunciados" (PÊCHEUX, 2002), mais precisamente a sua abrangência (pequeno, médio, grande), depois, o que ele poderia oferecer de análise para as questões do projeto, no entanto, deixei-me levar por outros enunciados, seguindo um pouco a intuição e um pouco as questões do projeto. Uma questão metodológica se colocou ao recortar o enunciado: tive que enumerá-los e fazer referência para ficar fácil de encontrar o contexto, caso fosse necessário. Tive que voltar várias vezes, seja para fazer um novo recorte, seja para aumentar ou diminuir o enunciado.

Recortei cerca de mil enunciados, depois fui classificando-os em discursos como "paráfrases" (FUCHS, 1982). Foi um trabalho cansativo devido à especificidade participava de vários discursos em cada enunciado. Esta classificação depende em parte do conhecimento do analista (seja de mundo, seja sobre o assunto ou, ainda, seja um conhecimento sobre 
questões de ordem política), pois envolve um certo olhar "político/ideológico" que muitas vezes não se manifesta na superfície do enunciado ou dos enunciados.

De acordo com Orlandi ${ }^{5}$, "não se trata de analisar o enunciado em si, mas sim analisar o que ele silencia”. Estas considerações obrigam a elaborar questões aos enunciados antes de classificá-los em discursos. No total, classifiquei cerca de trinta discursos, dos quais fiquei apenas com sete; apenas com aqueles que em seu conjunto poderiam melhor expressar um traço peculiar do movimento e se ofereciam melhor para análise. Até porque se fosse analisar todos eles, com certeza, não concluiria o mestrado no prazo previsto!

Uma vez decidido pelos sete discursos, iniciei o trabalho de indagar os enunciados em suas especificidades enquanto paráfrases um dos outros em maior ou menor "nível" de “sentido" (PÊCHEUX, 1997), ou seja, aqueles em é que possível classificar como enunciados pertencentes a um mesmo discurso ao serem indagados. Foi o momento também de reduzir o número de enunciados, ficando somente com os que ofereciam maior possibilidade de análise.

A análise de forma geral, num primeiro momento, inicia-se já no recorte dos enunciados; num segundo momento, temos a classificação dos discursos; já no terceiro momento, temos a confrontação das questões principais da dissertação (objetivos e problemáticas) em relação ao discurso a ser analisado, é um momento lento que depende de duas questões básicas: a primeira diz respeito à "habilidade" (ORLANDI, 1999) com que o analista trabalha as teorias e, a segunda, ao nível de conhecimento técnico ou de mundo que o analista possui sobre o "tema", isso de acordo com o tipo de análise que se pretende.

Se for uma análise de abordagem mais histórica (o que não exclui a "materialidade discursiva"), temos de procurar a relação do discurso em questão com outros discursos históricos e ver qual o tipo de relação há entre ambos, também analisar a "posição sujeito", os sentidos possíveis, os "deslocamentos", aquilo que faz com que o discurso seja igual e, ao mesmo tempo, diferente, ou seja, quais os sentidos que permanecem e o sentidos que deslizam para ser tornar um outro (PÊCHEUX, 2002).

Se for uma análise mais pautada na materialidade discursiva (o que não exclui o caráter histórico), é possível, entre outras considerações, analisar a demanda de sentidos, a "polissemia" (ORLANDI, 1999), o tipo de paráfrase, o que se mostra e o que silencia, isto sempre em relação aos outros. Mesmo que seja uma análise com ênfase e mais pautada nas

\footnotetext{
${ }^{5}$ Comentário feito quando ministrava uma disciplina em Análise do Discurso no IEL - Unicamp em 2004.
}

Interface da Educ.

\begin{abstract}
v. 1
\end{abstract}
n. 1

Paranaíba p. $66-82$ 2010 
materialidades discursivas, este fato não exclui a historicidade, ou seja, aquilo que Pêcheux (2002), concebe como "redes de memória".

É importante ressaltar o equilíbrio entre as duas abordagens analíticas. Importa, de acordo com Orlandi (1996, p. 23), considerar "a relação entre tipo e funcionamento, que é um instrumento decisivo para o analista, pois, em grande parte, a sua tarefa (explícita ou implícita) é distinguir modelos de discursos", a partir de dois pontos: o primeiro diz respeito às questões e perguntas que o analista precisa elaborar; o segundo é observar o que o próprio recorte "oferece" ao analista para além de suas questões e perguntas e outras questões, pois na linearidade dos enunciados, a cada "palavra" (PÊCHEUX, 1997), a cada sintagma, a cada fragmento, sempre há possibilidade de "algo" soltar aos olhos do analista.

No momento de analisar o discurso ocorre outro fato importante a ser considerado: de alguma forma o próprio discurso coloca questões para o analista, umas mais explícitas na superfície discursiva, outras mais complexas, que dependem de elaborações hipotéticas que poderão ou não ser sustentadas de acordo com a argumentação do analista. Em alguns momentos, pode ocorrer a "tentação" de forçar os dados na teoria ou vice-versa para tentar legitimar a análise. Isso é sempre um perigo para o analista, considerando que analisar é também trabalhar “na tensão das relações significativas”. (ORLANDI, 2001, p. 13).

Assim, gostaria de comentar que apesar da descrição até aqui parecer esquemática como se tudo estivesse pensado, organizado previamente, a questão metodológica foi se seguindo mais ou menos de forma intuitiva, na tentativa de encontrar "caminhos" e tentar sistematizar ou padronizar uma forma de analisar, uma forma de se deparar com os discursos e enunciados a partir das questões prévias e a partir das questões que os próprios discursos e enunciados colocavam a cada indagação. Isso é tão flagrante que o tópico metodologia ficou resumido a poucas linhas de forma sintética, pois, mesmo após o término das análises e considerações, foi possível explicitar detalhadamente como foi o processo de reflexão.

Com estas considerações, finalizo ainda que de forma insatisfatória as questões metodológicas da dissertação de mestrado.

\section{Questões Metodológicas: doutorado}

Se no tópico anterior as considerações foram post scriptum, uma vez que foi feita após a dissertação, este tópico já é um recorte na íntegra de tese de forma que serão feitas apenas algumas considerações breves sobre o recorte e objetivos. 
Seguem, de forma elementar, as considerações a respeito da problemática e dos objetivos da tese:

\begin{abstract}
O surgimento de um acontecimento discursivo não é um fato rotineiro, nem intencional e nem mesmo elaborado, mas constituído no bojo das relações de reprodução/transformação das relações de produção (PÊCHEUX, 1997, p. 191) sociais nas quais se dão os processos discursivos (idem, 161): um discurso novo é constituído no bojo das relações sociais políticas dadas as condições de produção (PÊCHEUX, 1969, p. 75).

Nesse sentido, o objeto específico de estudo desta pesquisa é o discurso da Reforma Agrária pela Ocupação, suas condições de irrupção, sua forma de materialização discursiva e seu efeito de sentido em relação a outros discursos já inscritos, pelo operariado, por exemplo. Considerando que o surgimento de um discurso não é acontecimento corriqueiro, proponho duas questões. A primeira diz respeito ao fato de esse discurso ser novo ${ }^{6}$. E como um discurso novo na história da luta pela terra no Brasil, outras questões se põem: a) que condições materiais de existência histórica propiciaram seu surgimento? b) Considerando esse surgimento uma ruptura em relação aos discursos anteriores na luta pela terra, como se deu essa ruptura? c) quais acontecimentos históricos a sua volta propiciaram sua irrupção? d) Na mesma medida, quais acontecimentos a sua volta tentaram evitar sua irrupção? e) quais temas, objetos, controle de sistema o constituíram em seu repertório discursivo? f) quais enunciados colocaram em prática "todo jogo de regras" que definem o que pode e o que não se pode constituir como elemento do discurso?

Estas são algumas das perguntas que norteiam a análise do discurso de Reforma Agrária pela Ocupação e as condições de existência do MST (RODRIGUES, 2007, p. 18-19).
\end{abstract}

Analisar discursos possui um princípio norteador: "toda descrição abre sobre a interpretação" (PÊCHEUX, 2002, p. 54) e/para que "através das descrições regulares de montagens discursivas, se possam detectar os momentos de interpretações enquanto atos que surgem como tomadas de posição [do analista] reconhecidas com tais, isto é, como efeitos de identificação assumidos e não negados" (idem, 57). Para Pêcheux (2002, p. 57), a interpretação é "uma questão de ética e política: uma questão de responsabilidade". Para Orlandi (1999, p. 64), a interpretação é uma questão de "capacidade analítica do pesquisador, pela habilidade que ele pratica a teoria, face a sua responsabilidade teórica”. A interpretação se constitui a partir de determinados procedimentos metodológicos, por mais elementares que sejam, como recortar um enunciado a ler e elaborar uma pergunta a seu respeito.

Considero que o discurso "é concebido como um fenômeno observável, um objeto empírico, constituído de uma seqüência linear de enunciados, é um acontecimento histórico" (CARDOSO, 1994, p. 211) e enquanto hipótese de trabalho, ele "serve apenas para certos fins teóricos de análise" (CARDOSO, 1994, p. 212). Os recortes do discurso em enunciados "não

\footnotetext{
${ }^{6}$ A questão de o discurso do MST ser novo ou não foi inicialmente abordada de forma introdutória na minha dissertação de mestrado (2001). Faço uma retomada dessa questão. A minha posição permanece a mesma: o MST funda um discurso novo.
} 
chegam a constituir um sistema, pois perdem sua "evidência" toda vez que questionamos sua validade. Os recortes são sempre interpretativos" (CARDOSO, 1994, p. 213).

A Análise do Discurso, no entanto, não possui uma metodologia específica, um modelo, um esquema já dado que permita ou possa apenas "enquadrar" os dados, nem uma forma de trabalhá-los. Isso significa que cabe ao analista adotar "princípios e procedimentos" (ORLANDI, 1999, p. 59), a partir das perguntas e dos objetivos em relação aos dados. A construção de dispositivos (ORLANDI, 1999, p. 59) de análise é condição, a princípio, para desenvolver um conjunto de práticas sobre os dados, de formas de trabalhar os dados que, por fim, se constituem em procedimentos metodológicos.

Talvez seja óbvio, mas analisar discurso coloca em questão o quê analisar: primeiro passo metodológico, que se desdobra "automaticamente" em algumas perguntas a fazer, um objetivo a construir, algumas hipóteses, um objeto do discurso, um corpus a ser recortado ou construído e, desse recorte, extrair somente o que for significativo e relevante para as questões elaboradas. Isso significa que em um dado corpus nem tudo vai ser analisado, porém não equivale a dizer que o que ficou de fora da análise não seja significativo ou relevante, mas apenas que são as perguntas, os objetivos, as hipóteses e o objeto do discurso que norteiam, em alguma instância, o recorte para análise.

É importante ressaltar que utilizarei o dado tipo rentável (POSSENTI, 2002, p. 31). A seleção dos dados que constituem o corpus é, em geral, um passo estratégico (metodológico) do analista, pois de acordo com Maingueneau (1993, p. 20), “cada corpus estabelece problemas específicos”. Ainda, a respeito do dado, de acordo com Possenti (2002, p. 33),

[...] o dado existe independentemente do pesquisador, por mais que seu status dependa da teoria. Afirmar que o dado existe independentemente do investigador não significa dizer que ele determine as opções e ações do investigador [...] é preciso admitir que o mundo existe independentemente da teoria.

O corpus é composto de editoriais dos boletins e dos jornais do MST que compreendem o período de 1981 (no. 01, 15/05/1981) até 2004, (no. 240, 05/2004). A escolha dos editoriais se deu em virtude de conterem, em seu aspecto e em seu formato material, de forma "objetiva" e assumida, as orientações, as propostas, os objetivos, as reflexões, as bandeiras e o programa político do movimento. Além disso, os editoriais constituem um lugar em que os discursos e as ideologias se materializam com certo efeito, força e poder.

Os editoriais do Boletim e do Jornal Sem Terra foram o primeiro recorte de universo de possibilidades ou de "universo discursivo" (MAINGUENEAU, 1993, p. 116). A escolha dos editoriais se justifica por ser um espaço privilegiado de orientação "programática", quer 
de jornais e revistas, de movimentos populares, de partidos políticos ou de jornais e de revistas de comunicação de massa; o editorial é um espaço que melhor expressa as orientações ideológicas assumidas ou não como posições ideológicas.

A entrada no corpus para proceder a outros recortes de enunciados nunca é fácil, os discursos não "falam” por si só. A entrada no corpus foi feita com a elaboração de algumas perguntas, com alguma intuição e também com um pouco de atenção para as incidências de "curiosidades discursivas" que a princípio não revelam possuir relação "direta" e "indireta" com os objetivos propostos, mas que no decorrer do contato e trabalho de "idas e vindas" com o corpus elas acabam, às vezes, por significar algo importante, isso aconteceu, mas não foi uma constante.

A partir das perguntas, localizei os recortes de enunciados que respondiam e possuíam alguma relação "direta" e "indireta" com os objetivos. Outro ponto importante é que no decorrer do contato com o corpus algumas perguntam iam sendo re-elaboradas e até mesmo abandonadas em detrimentos de outras. O contato com o corpus é um momento tenso para o analista.

É importante ressaltar que os enunciados em $\mathrm{AD}$ não equivalem à oração, à proposição, à frase ou aos atos de fala. A sua materialidade linguística pode coincidir como sintagmas verbais ou nominais ou com período composto de extensão relativa de um texto pequeno ou parágrafo. O enunciado ainda pode possuir em sua composição outras materialidades não linguísticas, como quadro, pintura, charge, tira de jornal, formas de composição, arte gráfica, cores etc.

A delimitação do enunciado é um trabalho do analista realizada, em grande maioria, a partir das perguntas e questões que já estão elaboradas previamente, mas que não são fixas, uma vez que o recorte não pode ser aleatório a ponto de causar algum tipo de estranhamento entre aquilo que o sujeito, em sua posição discursiva, materializou linguisticamente e aquilo que o analista recortou. Ou seja, tive o cuidado de, no recorte, não deturpar nem a estrutura linguística nem a linearidade construída pelo sujeito no "fio do discurso" (PÊCHEUX, 1997). O recorte dos enunciados pode ser considerado como uma etapa da análise muito significativa, uma vez que ao recortar os enunciados, o fiz já pensando naquilo que ele poderia oferecer de produtividade.

À medida que ia recortando os enunciados, cerca de mil, ia enumerando-os e fazendo referência ao corpus. Isso é importante porque no momento da análise, foi comum ter que voltar várias vezes ao corpus para verificar alguns aspectos dos enunciados em relação a sua 
linearidade, ou seja, o que tinha antes e o que tinha depois do recorte. Em muitos casos, no momento de análise, o recorte foi refeito, ampliado ou diminuído para focalizar melhor o direcionamento da análise. Essa estratégia apresenta uma vantagem de contar apenas com aquilo que é interessante para o analista, evita recortes grandes sem perspectiva de análise, mas que, para o possível leitor, pode apresentar questionamentos: por que não analisou isto ou aquilo etc.

É importante ressaltar que, no decorrer das análises, muitos enunciados foram abandonados ou porque eram paráfrases de outros "em maior ou menor grau" ou porque não faziam mais sentido. Nesse caso, cabe ao analista verificar quais dos enunciados se prestam melhor aos seus propósitos.

A quantidade de enunciados é em decorrência de dois fatores: o tamanho do corpus, editoriais de $1981, n^{\circ} 01$ até $2004, n^{\circ} 240$, eu queria poder olhar de uma perspectiva histórica abrangente, ou seja, queria constatar os discursos que iam se inscrevendo "a cada momento" de existência do Movimento e sua relação com a conjuntura. Essa proposta, no entanto, apresentou o inconveniente de "perder" o momento exato da enunciação, as "condições de produção do discurso" (PÊCHEUX, 1997), mas em contrapartida, ampliei e tentei descrever um contexto político mais amplo para compreender e relacionar às questões mais amplas de uma agenda política nacional. Acredito ter sido um ganho, porque pude verificar os discursos irem se inscrevendo, se repetindo, se parafraseando, se transformando gradativamente no repertório do MST em suas relações com a história. Foi uma opção metodológica trabalhar com um corpus considerável, se de um lado foi trabalhoso e cansativo, em contrapartida, pude escolher aqueles mais significativos às análises e aos agrupamentos provisórios; no total fiquei com seiscentos e noventa enunciados.

Depois de recortados, os enunciados ainda não falam por si só; a partir das perguntas e dos objetivos e também das descobertas (curiosidades e intuição) com o corpus, outras questões foram surgindo, mas não a ponto de abandonar os objetivos e propósitos que me levaram ao corpus. Caso isso ocorra, talvez o analista tenha outro projeto de pesquisa, ou a constituição do corpus não foi adequada. Um ponto fundamental antes de iniciar as análises foi após o recorte, quando comecei a refletir sobre o conjunto de enunciados em sua totalidade e esboçar um primeiro esquema geral da tese, primeiro em partes provisórias e depois em capítulos, já um pouco mais estáveis, mesmo que de forma elementar e provisória. Foi no decorrer das análises que as partes e os capítulos foram se constituindo e se configurando estavelmente. 
Assim, depois do recorte dos enunciados, fiz o esquema geral, ainda que elementar da tese. Fui separando conjuntos de enunciados de acordo com os objetivos e propósitos gerais; os agrupamentos de enunciados são sempre provisórios nesse primeiro momento, podendo até mesmo participar de vários agrupamentos.

Um aspecto importante dos enunciados é que eles se prestam a uma série de análises e abordagens de acordo com as perguntas que se faz a eles, de acordo com o agrupamento em que estão inseridos ou organizados. Ou seja, à medida que tenho várias perguntas ao mesmo enunciado, ele vai se prestando às análises. Não cheguei a esgotar analiticamente nenhum enunciado, confesso que fiquei predisposto, mas não o fiz, o que não quer dizer que não seja possível esgotá-lo.

Uma vez separado os agrupamentos por capítulos e/ou partes, fiz um outro recorte, a partir dos objetivos e delimitações específicos dos capítulos, ou seja, esquematizei os agrupamentos considerando suas especificidades. Assim, no decorrer das análises por capítulos ou partes, um retorno ao corpus foi uma constante, como também um reajustamento dos agrupamentos, considerando a exclusão de certos enunciados, inclusão de outros, e a redefinição linear ainda de alguns. Isso para atender à demanda das questões, dos objetivos e das perguntas.

Há uma tensão entre as questões, os objetivos e as perguntas em relação aos enunciados. Salvo os objetivos, desde que consistentes, eles não se alteram no contato com o corpus. Mas as questões e as perguntas não apenas no contato com o corpus, mas, sobretudo, no momento crucial das análises, elas e eles se constituem de uma relação ou um jogo tenso. Lembrava sempre de Pêcheux (2002, p. 57): “face às interpretações sem margens nas quais o intérprete se coloca como ponto absoluto, sem um outro nem real, trata-se aí, para mim, de uma questão de ética e política: uma questão de responsabilidade”. Em alguns momentos, os enunciados questionavam as questões e as perguntas como querendo dizer que elas não eram adequadas para eles; e em outros casos, a relação era inversa, as perguntas e as questões questionavam se de fato os enunciados possuíam algum tipo de relação com elas. Este momento é delicado e "perigoso", o que ocorre é um estranhamento, corre-se o risco de "forçar" ou construir uma análise sem consistência, sem um amparo quer nas materialidades discursivas, quer nas filiações históricas e redes de memória discursiva.

Como tinha como proposta uma perspectiva histórica, adotei metodologicamente o ponto de vista da progressão linear de enunciação na maioria dos agrupamentos para análise. Iniciei as análises pensando na progressão e desenvolvimento discursivo do movimento como 
condição de poder "capturar" momentos de "surgimento" de algo diferente, algo novo que ainda não havia se revelado nas práticas discursivas. Foi nesse sentido que foi possível analisar o desenvolvimento discursivo do movimento como a posição de sujeito histórico na ordem do Estado, como agricultor, para sujeito revolucionário que questiona o próprio Estado e assim se tornando o outro do Estado.

Analisei também os pontos de tensão discursiva, a constituição: posição sujeito, discursos, objetos, temas, transposições de espaço, interlocutores, constituição do instrumento discursivo, pontos de ruptura etc. A visão linear de enunciação favoreceu de forma considerável as análises. Aliás, a estrutura da tese e dos capítulos seguiu com certa regularidade este esquema.

Outro ponto importante foi a proposta metodológica de análise que privilegiei: uma abordagem equilibrada entre as materialidades discursivas e a abordagem histórica; pelo menos acredito ter conseguido. Esse fato é importante porque é comum em muitos trabalhos em Análise do Discurso, o analista privilegiar ou uma abordagem das materialidades discursivas ou uma abordagem mais histórica. Tive a impressão de que as escolhas metodológicas sempre implicam em perdas, quando optei por um período longo (1981 2004), perdi, por exemplo, em muitos casos, a conjuntura precisa de enunciação, tive, apenas, em alguma instância, aquilo que o conjunto de enunciados se referia como pontos de ancoragem históricos.

Assim, procurei não apenas analisar alguns aspectos das materialidades discursivas como também relacioná-las à historicidade que a constituem com as condições históricas que favorecem sua materialização discursiva e de tudo que pode decorrer. Ainda um último aspecto das análises, o conhecimento de alguns fatores históricos do analista se constitui em muitos casos de um fator significativo de ancoragem das materialidades discursivas e ancoragem histórica. Ou seja, certas especificidades dos enunciados, dos agrupamentos e/ou dos discursos dependem do tipo de conhecimento que o analista se imbuiu para elaborar questões, objetivos e adentrar nas análises.

A partir do exposto, é possível resumidamente elencar as etapas que constituem metodologicamente a análise, elas são as seguintes, não necessariamente nessa ordem:

a) definição: de objetivo, de objeto, elaboração de hipótese e perguntas a fazer;

b) proceder ao recorte de um corpus de todo corpora de um determinado universo discursivo (MAINGUENEAU, 1993, p. 116); 
c) a partir desse corpus e das questões da letra "a", proceder ao primeiro recorte de enunciados (PÊCHEUX, 1969, p. 100) e suas paráfrases (FUCHS, 1982, p. 29) significativas e relevantes (ainda que de forma intuitiva) que possam ser material de análise. É importante enumerar esses recortes e fazer as devidas referências ao corpus;

d) agrupar os enunciados considerando suas especificidades de sentidos, de objetos e de temas materializados nos discursos;

e) classificar os grupos de enunciados em discursos, dando-lhes uma configuração;

f) analisar os discursos (enunciados desse discurso) quanto a sua posição ideológica, sua relação com outros discursos, redes de filiações históricas quanto ao interdiscurso e à memória discursiva;

g) analisar nos discursos as posições do sujeito nas suas relações com as estruturas sociais;

h) analisar agrupamentos de enunciados independentemente de se constituírem em discursos com o objetivo de verificar certas especificidades: analisar a "progressão e transformação" de sentidos considerando a sua materialidade; analisar conjuntos de enunciados que marcam aspectos da identidade dos sujeitos; analisar conjuntos de enunciados que materializam objetos e temas de discurso;

i) proceder a um segundo recorte, o de exclusão de enunciados, pois durante o percurso das análises, constata-se que alguns dos enunciados não foram analisados, ou porque havia outros que se "prestavam" melhor a análise, ou porque, durante o percurso de análise, eles deixaram de fazer sentido;

j) voltar ao corpus para efetuar um outro recorte específico a partir de certos enunciados. Qualquer tentativa de agrupamento de certo conjunto de enunciados, provoca exclusão de outros enunciados, no entanto, é importante considerar que os agrupamentos são, em alguma medida, instáveis e, por isso, podem revelar algum ponto de vista do analista. Os agrupamentos são sempre provisórios e instáveis se o discurso mudar em decorrência de sua relação tensa com outros grupos de enunciados ou conjuntura política distinta, que ressignificam algumas unidades que aparentemente eram consideradas como estáveis em relação aos sentidos.

Assim, a metodologia foi sendo construída ao longo do trabalho e face à própria demanda dos objetivos e dos objetos da pesquisa. É importante ressaltar que tive a "impressão" que o percurso metodológico de um lado se apresentava produtivo, no entanto, de outro, parecia que "perdia" algo por seguir este ou aquele caminho. Considero, ainda que 
elementarmente, que este fato metodológico se constitui em um dos procedimentos próprios da análise do discurso, uma característica peculiar face à teoria, ao objeto, ao objetivo e ao analista.

\section{Considerações Finais}

A questão metodológica ou como fazer análise em Análise do Discurso tem sido um certo tipo de "problema". Apesar de algumas reflexões de pesquisadores Orlandi (2001, 1996, 1999), Possenti (2002) e Voese (2004), ainda é possível constatar a "tensão" do aluno de pósgraduação ou iniciante em Análise do Discurso no momento de demonstrar sua habilidade de analista na aplicação teórica, ou seja, no momento de efetuar propriamente a análise.

A AD, ao se constituir enquanto disciplina, opõe-se a algumas correntes filosóficas, por exemplo: o positivismo e a fenomenologia. De acordo com Triviños (2008, p. 41):

[...] o positivismo, sem dúvida, representa através de suas formas neopositivistas, como o positivismo lógico e a denominada filosofia analítica, uma corrente de pensamento que alcançou, de maneira singular na lógica formal e na metodologia da ciência, avanços muitos meritórios para o desenvolvimento do conhecimento.

A outra corrente com a qual promove ruptura é a fenomenologia, que segundo Trivinõs (2008, p. 47-48),

[...] a fenomenologia exalta a interpretação do mundo que surge intencionalmente à nossa consciência. Por isso, na pesquisa, eleva o ator, com suas percepções dos fenômenos, sobre o observador positivista.

$[\ldots]$

A fenomenologia, sem dúvida, representa uma tendência filosófica que, entre outros méritos, parece-nos, tem o de haver questionado os conhecimentos positivistas, elevando a importância do sujeito no processo da construção do conhecimento.

Ao se opor ao positivismo e à fenomenologia, a $\mathrm{AD}$ não o faz em um campo do saber neutro, ou para além das ciências. Ela se situa no marxismo, naquilo que ele pode oferecer de uma reflexão "crítica" da realidade a partir de algumas posições teóricas que para Trivinõs (2008, p. 50-51),

[...] a importância que apresenta para o marxismo a concepção materialista da realidade torna necessário referir-se brevemente ao materialismo filosófico, já sabemos que ele considera que a matéria é o princípio primordial e que o espírito seria um aspecto secundário. A consciência, que é um produto da matéria, permite que o mundo se reflita nela, o que assegura a possibilidade que tem o homem de conhecer o universo. A idéia materialista do mundo reconhece que a realidade existe independentemente da consciência.

[...]

O materialismo dialético é a base filosófica do marxismo e como tal realiza a tentativa de buscar explicações coerentes, lógicas e racionais para os fenômenos da natureza, da sociedade e do pensamento.

Interface da Educ.

Paranaíba

V. 1

n. 1

p. $66-82$

2010 
Por um lado o materialismo dialético tem uma longa tradição na filosofia materialista e, por outro lado, que é também antiga concepção na evolução das idéias, baseia-se numa interpretação dialética do mundo.

[...]

O materialismo histórico é a ciência filosófica do marxismo que estuda as leis sociológicas que caracterizam a vida da sociedade, de sua evolução histórica e da prática social dos homens, no desenvolvimento da humanidade. O materialismo histórico significou uma mudança fundamental na interpretação dos fenômenos sociais que, até o nascimento do marxismo, se apoiava em concepções idealistas da sociedade humana. [...] O materialismo histórico ressalta a força das idéias, capaz de introduzir mudanças nas bases econômicas que as originou.

Assim, a AD se beneficia dessas reflexões, necessariamente do materialismo histórico, naquilo que importa para compreender uma reflexão "crítica" do discurso, do sujeito, da língua/linguagem. A AD vai interrogar os estudos linguísticos pela historicidade dos discursos, dos sujeitos e das formações sociais, mais ou menos o que Saussure (1990) excluiu em suas dicotomias para a Linguística se constituir em ciência.

Estas questões estão na base da $\mathrm{AD}$, quando ela relaciona a Linguística, o Materialismo Dialético e a Psicanálise para trabalhar no espaço limite entre o social e o linguístico. Disso, resulta não apenas um novo campo de reflexão, mas necessariamente uma proposta metodológica sem esquemas e modelos estruturados, situação que impõe ao analista uma diversidade de questões de como analisar em Análise do Discurso.

\section{Referências}

ALTHUSSER, L. Aparelhos Ideológicos do Estado. 7. ed. Rio de Janeiro: Edições Graal, 1985.

CARDOSO, S. H. B. Realidade dos sentidos: dos jecas aos sem-terra. In: ABRALIN: Boletim da Associação Brasileira de Lingüística. Fortaleza: Imprensa Universitária/UFC, 2003. p. 669-671. V. 1.

Discurso e ensino. Belo Horizonte-MG: Autêntica, 1999a.

Ideologia: um conceito obsoleto? In. GEL - Grupo de Estudos Lingüísticos. São

Paulo-SP, V. 28, 1999b. p. 379-84.

Demonstrativo, dêixis e interdiscurso. 1994. 278f. Tese (Doutorado em Ciências) Universidade Estadual de Campinas. Instituto de Estudos da Linguagem, Campinas, 1994.

COURTINE, J-J. A metamorfose do discurso político. São Carlos-SP: Claraluz editora, 2006.

DE CERTEAU, M. A invenção do cotidiano: artes de fazer. 7 ed. Petrópolis-RJ: Vozes, 2002. V.1. 
EAGLETON, T. Ideologia: uma introdução. São Paulo: Boitempo, 1997.

FUCHS, C. A paráfrase, entre a língua e o discurso. Language Française. Larousse, n. 53, 1982.

GERALDI. J. W. A diferença identifica. A desigualdade deforma. Percursos bakhtinianos de construção ética através da estética. Campinas-SP, UNICAMP, 2002. mimeo.

Depois do 'show', como encontrar o encantamento? Cadernos de Estudos

Lingüísticos, Unicamp, n. 44, p. 251-261, jan./jun., 2003.

et al. O ensino de língua portuguesa. 2. ed. São Paulo: Atual Editora, 1986.

LAGAZZI-RODRIGUES, S. A discussão do sujeito no movimento do discurso. 121f. Tese (Doutorado em Linguística) - Universidade Estadual de Campinas. Instituto de Estudos da Linguagem, Campinas, 1998.

O desafio de dizer não. Campinas-SP: Pontes, 1988.

MAINGUENEAU, D. Novas tendências em análise do discurso. 2 ed. Campinas-SP: Pontes, 1993.

Análise de textos de comunicação. São Paulo: Cortez, 2001.

MALINOWSKI, B. I. Objetivos, método e alcance desta pesquisa. In: GUIMARÃES, A (Org.). Desvendando as máscaras sociais. 2. ed. Rio de Janeiro: Livraria Francisco Alves Editora, s/d. pp. 39-61

MARX, K. e ENGELS, F. Manifesto do Partido Comunista. 3. ed. Petrópolis-RJ: Vozes, 1990.

O 18 Brumário e cartas a KugelmannI. 6. ed. Rio de Janeiro: Paz e Terra, 1997.

A ideologia alemã. São Paulo: Martins Fontes, 1998.

ORLANDI, E. P. Discurso e texto: formação e circulação dos sentidos. Campinas: Pontes, 2001.

Análise de discurso: princípios e procedimentos. Campinas: Pontes, 1999.

As formas do silêncio: no movimento dos sentidos. 4. ed. Campinas-SP: Editora da UNICAMP, 1997.

Maio de 1968: os silêncios da memória. In: PÊCHEUX, M. et al. Papel da Memória. São Paulo: Pontes, 1999. p. 59-71.

PÊCHEUX, M. Semântica discursiva: uma crítica à afirmação do óbvio. Campinas-SP: Editora da UNICAMP, 1997. 
. (Org.) Gestos de leitura. 2. ed. Campinas-SP: Editora da Unicamp, 1997.

. O discurso: estrutura ou acontecimento. 3. ed. Campinas-SP: Pontes, 2002.

Papel da Memória. In: ACHARD, P. et al. Papel da Memória. Campinas: Pontes, 1999. p. 49-56.

III Análise automática do discurso (AAD-69). In: Por uma análise automática do discurso: uma introdução à obra de Michel Pêcheux. 3. ed. Campinas-SP: Editora da Unicamp, 1997. p. 61-161.

PÊCHEUX, M. e FUCHS, C. A propósito da Análise Automática do Discurso: atualização e perspectivas. In: . Por uma análise automática do discurso: uma introdução à obra de Michel Pêcheux. 3. ed. Campinas-SP: Editora da Unicamp, 1997. p. 163-252.

POSSENTI. S. Discurso, estilo e subjetividade. 2. 'ed. Campinas-SP: Martins Fontes, 2001. . Ainda sobre a noção de efeito de sentido. In: GREGOLIN, M. R. et al. (Org.). Análise do discurso: as materialidades do sentido. São Carlos-SP, Claraluz, 2001. p. 45-59. Os limites do discurso. Curitiba-PR: Criar Edições, 2002.

Teoria do discurso: um caso de múltiplas rupturas. In. MUSSALIN, F. e BENTES, A. C. Introdução à lingüística. Fundamentos epistemológicos 3. ed. São Paulo-SP: Cortez, 2004. p. 353-392.

RAJAGOPALAN, K. Por uma lingüística crítica: linguagem, identidade e a questão ética. São Paulo: Parábola Editorial, 2003.

. A construção de identidades e a política de representação. In: FERREIRA, L. M. A. e ORRICO, E. G. (Org.) Linguagem, identidade e memorial social. Novas fronteiras, novas articulações. Rio de Janeiro: DP\&A Editora, 2002. p. 77-88.

RODRIGUES. M. L. Introdução ao estudo da ideologia que sustenta o MST. 2001. Dissertação (Mestrado em Linguística) - Universidade Federal de Mato Grosso do Sul, Três Lagoas - MS, 2001. 